\title{
HIV incidence and sexual behavioral correlates among 4578 men who have sex with men (MSM) in Chengdu, China: a retrospective cohort study
}

Xinyi You ${ }^{1+}$, Stuart Gilmour2+, Wangnan Cao ${ }^{3}$, Joseph Tak-fai Lau ${ }^{4}$, Chun Hao ${ }^{1,5^{*}}$, Jing Gu ${ }^{1,5}$, Phuong Mai Le ${ }^{2}$, Liping Peng ${ }^{1}$, Dannuo Wei ${ }^{1}$, Yang Deng ${ }^{1}$, Xiaodong Wang ${ }^{6}$, Huachun Zoư ${ }^{7}$, Jibin Li ${ }^{8}$, Yuantao Hao ${ }^{1,5}$ and Jinghua $\mathrm{Li}^{1,5^{*}}$ (D)

\begin{abstract}
Background: The prevalence of HIV among men who have sex with men (MSM) in southwest China is still increasing. This study aimed to investigate the trend in HIV incidence and its associated risk factors among MSM in Chengdu, China.

Method: Incidence data were collected from the largest local non-governmental organization (NGO) serving MSM in Chengdu between 2012 and 2018, while information on sexual behaviors was collected from 2014. All MSM who received voluntary counseling and testing services $(V C T)$ in the collaborating NGO at least twice during the study period were included. We calculated the HIV incidence density among MSM every 2 years and the overall incidence rate. A Cox proportional hazards regression model was employed to identify risk factors for HIV infection.
\end{abstract}

Result: A total of $4578 \mathrm{HIV}$-negative participants were included in the cohort. The total incidence density was 5.95 (95\% Cl: 5.37-6.56)/100 person-years (PYs) between 2012 and 2018. The segmented incidence density was 9.02 (95\% Cl: 7.4610.78), 5.85 (95\% Cl: 4.86-6.97), 5.43 (95\% Cl: 4.53-6.46), and 3.09 (95\% Cl: 2.07-4.41)/100 PYs in 2012-2013, 2014-2015, 2016-2017, and 2018, respectively. After adjusting for sociodemographic characteristics, compared to participants without sexual partners within 6 months, MSM with one fixed partner (Adjusted Hazard Ratio, AHR $=1.18,95 \%$ Cl: 0.44-3.19) and more than five partners ( $\mathrm{AHR}=2.24,95 \% \mathrm{Cl}: 0.81-6.20$ ) had increased risk of HIV infection. MSM who used condom inconsistently had a higher risk of HIV infection ( $A H R=1.87,95 \%$ Cl: 1.46-2.38) compared to consistent condom users.

Conclusion: The decreased HIV incidence density among MSM was potentially related to the successful comprehensive HIV prevention strategies in Chengdu. Multiple male sexual partnerships and inconsistent condom use during anal intercourse were risk factors associated with HIV occurrence.

Keywords: HIV/AIDS, Incidence, Men who have sex with men, Cohort studies, Sexual behavior

\footnotetext{
* Correspondence: haochun@mail.sysu.edu.cn; lijinghua3@mail.sysu.edu.cn

${ }^{+}$Xinyi You and Stuart Gilmour contributed equally to this work.

'School of Public Health, Sun Yat-sen University (North Campus), No.74,

Zhongshan second road, Guangzhou, China

Full list of author information is available at the end of the article
}

C C The Author(s). 2021 Open Access This article is licensed under a Creative Commons Attribution 4.0 International License, which permits use, sharing, adaptation, distribution and reproduction in any medium or format, as long as you give appropriate credit to the original author(s) and the source, provide a link to the Creative Commons licence, and indicate if changes were made. The images or other third party material in this article are included in the article's Creative Commons licence, unless indicated otherwise in a credit line to the material. If material is not included in the article's Creative Commons licence and your intended use is not permitted by statutory regulation or exceeds the permitted use, you will need to obtain permission directly from the copyright holder. To view a copy of this licence, visit http://creativecommons.org/licenses/by/4.0/ The Creative Commons Public Domain Dedication waiver (http://creativecommons.org/publicdomain/zero/1.0/) applies to the data made available in this article, unless otherwise stated in a credit line to the data. 


\section{Background}

HIV/AIDS is a growing public health problem worldwide and in China, with a total of over 32 million people living with HIV/AIDS (PLWH) globally [1, 2]. The national statutory infectious diseases report showed that HIV/AIDS has always been the infectious disease with the highest rate of death in the past decade in China [3]. It is estimated that there were a total of $850,000 \mathrm{PLWH}$ in the Chinese mainland by the end of 2018, accounting for $0.037 \%$ of the Chinese population $[4,5]$.

The national surveillance system reported that sexual transmission, especially male-to-male homosexual transmission, has become the major HIV transmission route in China [4, 6, 7]. The proportion of new HIV/AIDS cases reported yearly among MSM increased by more than 10 times in the last decade, from $2.5 \%$ in 2006 up to $28.3 \%$ in 2015 [8]. Studies have shown a rising trend in HIV prevalence among MSM, from $5.0 \%$ in 2009 to $6.9 \%$ in 2018 [9].

$\mathrm{HIV}$ incidence is the rate of new infections in a population in a specified time period and is a critical HIV surveillance indicator [10]. Calculation of HIV incidence is important to monitor trends in the HIV epidemic, and to evaluate interventions for HIV prevention [11]. However, compared to HIV prevalence studies, HIV incidence studies among Chinese MSM are limited, especially after 2015. Around 80 studies that reported HIV incidence rate/density among MSM in China have been identified, of which 12 were conducted in Sichuan and Chongqing (2006-2015), 12 were conducted in Jiangsu (2007-2015), and 14 were conducted in Beijing and Tianjin (2003-2015), but only one study [12] reported the incidence rate after 2015 (2008-2016) and only in Beijing. HIV incidence density is defined as the average incidence over a certain period of time. Its numerator is the number of persons newly diagnosed with HIV in the given period. The denominator of incidence density is the sum of person-time provided by observed participants [13]. The HIV incidence rate is defined as the number of new infections in the targeted population, usually expressed as a rate of infection per 100 persons per unit time [14]. Among these incidence studies, the majority used a repeated cross-sectional design [15], and only 30 studies used a cohort study design [8, 16]. The most updated meta-analysis calculated the pooled HIV incidence among Chinese MSM at 5.61/100 person years (PYs), with an increasing trend over time (5.29/100PYs in 2009-2011, 5.50/100PYs in 2012-2014) [17]. The pooled incidence value is the HIV incidence density calculated by meta-analysis [17]. The incidence density since 2015 among Chinese MSM is not well studied, even though testing and treatment strategies have expanded rapidly over that time period, and incidence studies are essential tools for understanding the impact of these strategies on the HIV epidemic [18].
The city of Chengdu has a population of more than 10 million urban residents and many migrant workers from other parts of China. Previous studies reported consistently high HIV incidence among MSM in Chengdu (8.92/100PYs, $95 \% C I=7.38-10.46 / 100 P Y s)$ between 2011 and 2015, which is much higher than the number reported in other cities within Sichuan province $(5.16 / 100 \mathrm{PYs}, 95 \% C I=4.65-5.66 / 100 \mathrm{PYs})$ and the national level (5.0/100PYs, 95\%CI $=4.1-5.8 / 100 \mathrm{PYs})$ $[19,20]$. The situation after 2015 is unknown.

A series of prevention and control measures targeted at MSM were implemented in the 2010 s by the local center for disease control and prevention (CDC) and non-governmental organizations in Chengdu [21-23], especially in the era of universal testing and antiretroviral treatment (ART). It is essential for policy makers to have an updated understanding of the HIV incidence trend and its risk correlates to better inform these prevention plans and programs [24].

This study aimed to update the trend in HIV incidence density among MSM in Chengdu until 2018, as well as to verify the association between sexual behavior-related factors and HIV seroconversion. Our findings will provide policy makers with evidence to propel sexual behaviorrelated prevention strategies to control the HIV epidemic among MSM.

\section{Methods}

\section{Overall study design}

A retrospective cohort study of trends in HIV incidence among MSM was conducted in Chengdu from 2012 to 2018, with the assistance of the Chengdu Tongle Health Consulting Service Center, which is the largest local gayfriendly non-governmental organization (NGO). This NGO is responsible for $80-90 \%$ of voluntary counseling and testing services (VCT) among MSM since its establishment in Chengdu. HIV testing was implemented by CDC doctors stationed at the NGO, and a total of 29,244 HIV tests were conducted from 2012 to 2018. Face-to-face interviews about sexual behaviors have been implemented since 2014 by NGO staff as a part of pre-test counselling. HIV testing and questionnaire results were linked with the participant's mobile number, which was unique and used as the proxy for an identifier to match the HIV testing results to each participant. Participants' mobile number was recoded into an unidentifiable ID number to make the dataset anonymous. Informed consent was obtained from all participants. HIV testing and the questionnaire survey were both routine activities of the NGO, and were not implemented as part of this research study.

\section{Study population and setting}

The target population of our study was MSM who received VCT at the collaborating NGO and lived in Chengdu at the 
time of the test. Eligible criteria for study enrollment included: 1) aged 16 years and above; 2) males who ever had oral or anal sex with other male(s) during their lifetime; 3 ) self-reported serological status was HIV-negative or unknown at the study enrollment; and 4) had at least two HIV testing records in the collaborating NGO during the study period.

\section{Questionnaire interview}

The questionnaire included two parts. The first part collected information on sociodemographic characteristics such as age, residential district, education, marital status and mobile number. The second part collected information on sexual behaviors in the past 6 months. Questions on sexual behaviors included number of fixed, casual or commercial male sexual partners, primary venue to find sexual partners (e.g., bars, bathhouses, parks/public toilets, online chat rooms, BBS, mobile dating apps), and frequency of condom use (i.e., never, sometimes, every time).

\section{Statistical analysis}

Descriptive analyses were conducted to show the sociodemographic characteristics of participants. Categorical variables were reported as both number and percentage, while continuous variables were presented as "mean \pm standard deviation". The midpoint between the date of the last negative and the first positive test was assumed to be the onset date of HIV infection in our analysis. HIV incidence density and its $95 \%$ confidence interval $(95 \% \mathrm{CI})$ was calculated with person-years (PYs) over the observed time as the denominator, assuming a Poisson distribution $[25,26]$. Chi-square tests were used to compare behavioral characteristics between participants with positive and negative HIV serostatus. Marginally significant variables $(p \leq 0.10)$ in univariate analysis were included in a multivariate Cox proportional hazards regression model to identify risk behavior factors associated with HIV incidence [27] after adjusting for sociodemographic characteristics. All analyses were performed using both IBM SPSS software Version 25.0 (SPSS Inc., Chicago, IL USA) and SAS Version

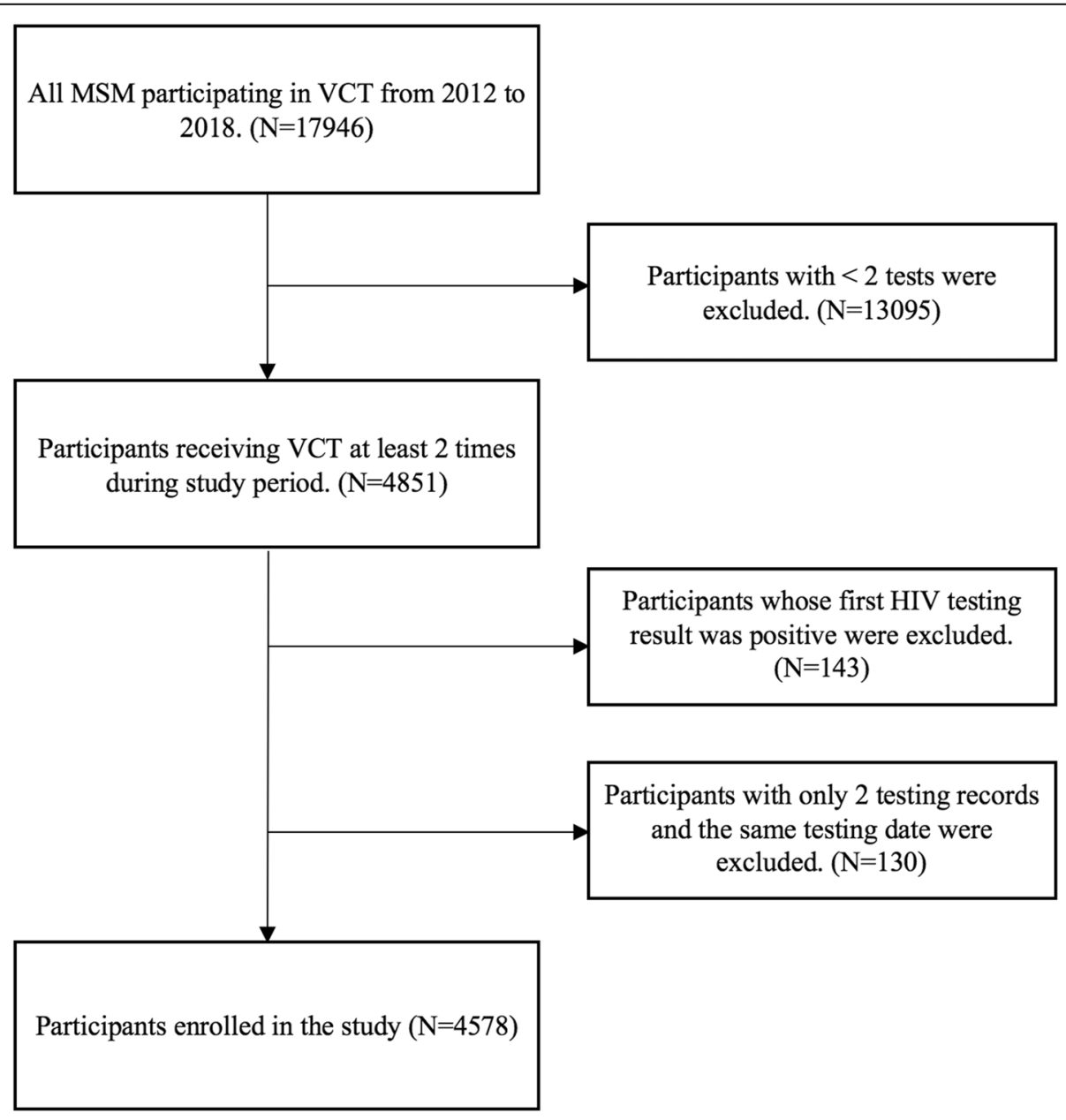

Fig. 1 Retrospective cohort study screening process, 2012-2018 
9.4 (Cary, North Carolina, USA). A two-tailed $p<0.05$ was considered to be statistically significant.

\section{Results}

\section{Demographic characteristics}

A total of 4578 HIV-negative MSM with at least two HIV testing records were identified and included in our cohort (Fig. 1). Of 4578 HIV-negative MSM who were enrolled in this retrospective cohort study, 3168 (69.2\%) MSM were younger than 30 years old, and 1066 (23.3\%) were between 31 and 45 years old. Two thirds (64.9\%) of the participants had a college degree or above. The majority $(76.8 \%)$ of the participants were single when enrolled at baseline (Table 1).

Table 1 Participants' baseline characteristics between 2012 and 2018

\begin{tabular}{|c|c|}
\hline Characteristics & $\mathrm{N}(\%)$ \\
\hline \multicolumn{2}{|l|}{ Age (years old) ${ }^{a}$} \\
\hline$\leq 30$ & $3168(69.2)$ \\
\hline $30-45$ & $1066(23.3)$ \\
\hline $46-59$ & $287(6.3)$ \\
\hline$\geq 60$ & $57(1.2)$ \\
\hline \multicolumn{2}{|l|}{ Education $^{a}$} \\
\hline Junior high school or less & $573(12.5)$ \\
\hline Senior high school/secondary technical school & $1036(22.6)$ \\
\hline College or higher & $2969(64.9)$ \\
\hline \multicolumn{2}{|l|}{ Marital status ${ }^{a}$} \\
\hline Single & $3517(76.8)$ \\
\hline Married with a woman & $842(18.4)$ \\
\hline Divorced/widowed & $219(4.8)$ \\
\hline
\end{tabular}

$\begin{array}{ll}\begin{array}{l}\text { Number of male sexual partners in the } \\ \text { past } 6 \text { months }\end{array} \\ \text { Zero } & 250(7.0) \\ \text { One fixed male sexual partner } & 1140(31.9) \\ \text { Multiple male sexual partners } & 2189(61.2)\end{array}$

Primary venue to find sexual partners ${ }^{b}$

No male sexual partners

$222(6.2)$

Offline

$745(20.8)$

Online

Money boys from clubs

$1449(40.5)$

$1074(30.0)$

Other venues

$89(2.5)$

Condom use during anal intercourse in the past 6 months ${ }^{b}$

\begin{tabular}{ll} 
Never & $225(6.3)$ \\
Sometimes & $1352(37.8)$ \\
Every time & $1575(44.0)$ \\
No anal intercourse & $427(11.9)$ \\
\hline
\end{tabular}

a The baseline characteristics data were collected since $2012(N=4578)$

${ }^{\mathrm{b}}$ These baseline characteristics data were collected since $2014(N=3579)$

\section{Sexual behaviors}

Among 3579 MSM (enrolled after 2014) with information on sexual behaviors, $7.0 \%$ had no partners in the past 6 months, $31.9 \%$ had one partner, and $61.2 \%$ had two or more male sexual partners. The primary venue to find sexual partners was through online apps (40.5\%), followed by money boys from clubs (30.0\%) and offline (20.8\%). Less than half (44.0\%) of the participants reported consistent condom use during anal intercourse in the past 6 months while $6.3 \%$ never used a condom (Table 1).

\section{HIV incidence density}

Between 2012 and 2018, a total of 381 HIV seroconversions were detected with 6406 person-years (PYs) observed. The overall HIV incidence density was 5.95 per 100 PYs (95\%CI: 5.37-6.56) (Table 2). The segmented incidence density was 9.02 (95\%CI: 7.46-10.78), 5.85 (95\%CI: 4.866.97), 5.43 (95\%CI: 4.53-6.46), and 3.09 (95\%CI: 2.07-4.41) per 100 PYs in 2012-2013, 2014-2015, 2016-2017, and 2018 respectively. The HIV incidence density among MSM showed a decreasing trend since 2012 (Fig. 2).

\section{Sexual behaviors associated with HIV incidence}

The variable measuring primary method of finding sexual partners was not statistically significant in the univariate and multivariate regression analyses, and was excluded from the final model. Multiple male sexual partners and inconsistent condom use were both risk factors for HIV incidence in the multivariable analysis. After adjusting for sociodemographic characteristics, compared to participants without sexual partners within the last 6 months, MSM with one fixed partner (Adjusted Hazard Ratio, AHR $=1.18,95 \% C I$ : 0.44-3.19), with two to five sexual partners $(\mathrm{AHR}=1.51,95 \% C I$ : $0.56-4.05)$ or with more than five partners $(\mathrm{AHR}=2.24$, 95\% CI: 0.81-6.20) had increased risk of HIV infection. MSM who used condom inconsistently during anal intercourse had higher risk of HIV infection (AHR = 1.87, 95\%CI: 1.46-2.38) compared to consistent condom users (Table 3).

\section{Discussion}

The study found that the incidence of HIV among MSM in Chengdu, a first-line megacity in southwest China, showed a declining trend from 2012 to 2018, but still remained at a high level. The continuous decrease in HIV incidence suggested good progress in HIV prevention measures in Chengdu, but the overall high HIV incidence density suggested that MSM are still at high risk of HIV infection.

HIV incidence identified in this study was slightly higher, compared to the meta-analysis result of HIV incidence among MSM in China (5.0/100PYs) published 
Table 2 HIV incidence density of MSM in Chengdu between 2012 and 2018

\begin{tabular}{lllll}
\hline Year & Number of Seroconversions, $\mathbf{n}$ & Observed person-years (PYs) & Incidence Per $\mathbf{1 0 0 ~ P Y s ~}$ & $\mathbf{9 5 \%} \mathbf{C l}$ \\
\hline $2012-2013$ & 113 & 1253 & 9.02 & $(7.46-10.78)$ \\
$2014-2015$ & 119 & 2034 & 5.85 & $(4.86-6.97)$ \\
$2016-2017$ & 122 & 2245 & 5.43 & $(4.53-6.46)$ \\
2018 & 27 & 874 & 3.09 & $(2.07-4.41)$ \\
Total & 381 & 6406 & 5.95 & $(5.37-6.56)$ \\
\hline
\end{tabular}

in 2015 [19]. MSM in Chengdu remain a vulnerable subpopulation for HIV infection, and should be considered as a priority for HIV/AIDS intervention projects. There are ongoing HIV control efforts among MSM in Chengdu, including enhanced VCT, universal ART, condom promotion, and other behavioral interventions. More prevention options and efforts should be made available to the high-risk group of MSM, such as preexposure prophylaxis (PrEP).

Previous studies conducted in some megacities/provinces have also shown high HIV incidence among MSM, for example, $5.16 \%$ in Sichuan in southwest China from 2011 to 2015 and 6.0/100PYs to 7.8/100PYs in Beijing during 2012 and 2015 [28, 29]. A cohort study in Hangzhou, a developed second-line city in eastern China, reported an HIV incidence of 6.6/100PYs among MSM between 2014 and 2015 [16]. The segmented incidence density in this time period among MSM in Chengdu was $5.85 / 100 \mathrm{PYs}$, which was lower than some other first-line and second-line cities in China.
The declining trend in HIV incidence identified in this study was similar to trends observed globally. The overall rate of HIV incidence among MSM in Chengdu was higher than the rate in the USA during 2009-2015 (4.11/100PYs) [27], and also higher than the rate in India (0.87/100PYs) [27] in 2012, and in Australia (0.048/ 100PYs) [30] in 2016. Higher rates have been observed in Myanmar in 2016 with 10.1/100PYs [27], followed by four African countries in 2017 with 6.96/100PYs [15]. Total time under observation among MSM in this study was larger compared to similar studies in Australia, the USA and the Netherlands [31] (with 4100, 632 and 171 person-years respectively), suggesting that this incidence study is one of the largest and most robust studies to have been conducted in a single city globally, offering high precision in its estimates and trends.

The current study found that multiple male sexual partners and inconsistent condom use are risk factors of HIV incidence among MSM, which are consistent with many existing studies [32]. We conducted additional

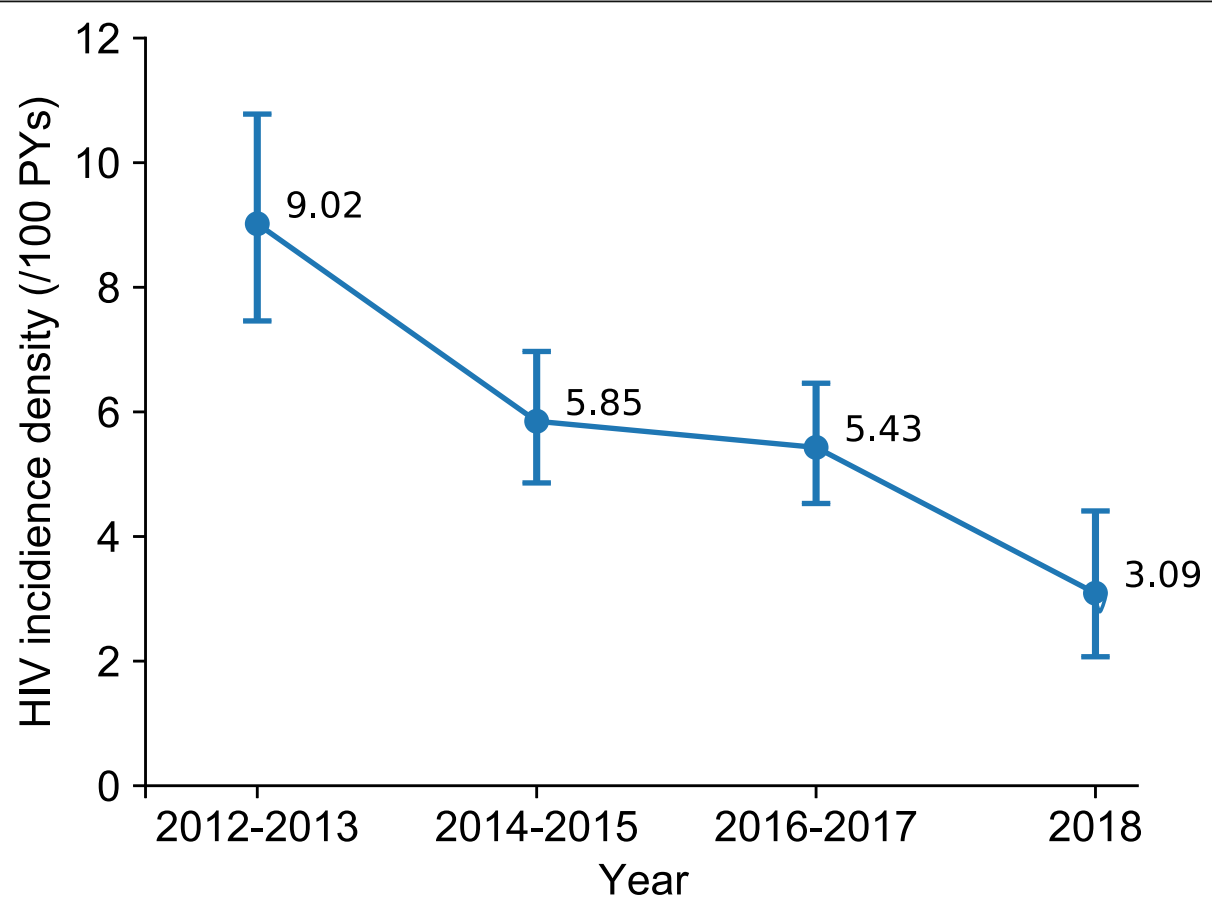

Fig. 2 Trend in HIV incidence density and 95\% confidence interval among Chengdu MSM from 2012 to 2018 
Table 3 Sexual behaviors associated with HIV incidence among participants

\begin{tabular}{|c|c|c|c|c|}
\hline Characteristics & $\begin{array}{l}\text { Number of Seroconversion, } \\
\mathrm{n} \text { (row \%) } \\
N=\mathbf{2 8 8}(\mathbf{8 . 0 \% )}\end{array}$ & $\begin{array}{l}\text { Unadjusted HR } \\
(95 \% C l)\end{array}$ & $\begin{array}{l}\text { Adjusted HR }{ }^{a} \\
(95 \% C l)\end{array}$ & $p$ value \\
\hline Age & & & & 0.244 \\
\hline$\leq 30$ & $157(6.6)$ & 1.00 & 1.00 & \\
\hline $30-45$ & $89(10.1)$ & $1.17(0.90-1.52)$ & $0.91(0.66-1.27)$ & 0.594 \\
\hline $46-59$ & $32(11.5)$ & $1.23(0.84-1.80)$ & $0.88(0.55-1.42)$ & 0.606 \\
\hline$\geq 60$ & $10(27.8)$ & $2.67(1.41-5.08)$ & $1.76(0.85-3.61)$ & 0.126 \\
\hline Education & & & & $<0.001$ \\
\hline Junior high school or less & $61(15.4)$ & $2.31(1.72-3.11)$ & $1.95(1.40-2.73)$ & $<0.001$ \\
\hline Senior high school/secondary technical school & $65(9.4)$ & $1.36(1.02-1.81)$ & $1.31(0.97-1.76)$ & 0.080 \\
\hline College or higher & $162(6.5)$ & 1.00 & 1.00 & \\
\hline Marital status & & & & 0.416 \\
\hline Single & $186(6.9)$ & 1.00 & 1.00 & \\
\hline Married & $69(10.2)$ & $1.24(0.94-1.63)$ & $0.98(0.67-1.44)$ & 0.932 \\
\hline Divorced/widowed & $33(16.1)$ & $1.71(1.18-2.49)$ & $1.29(0.82-2.03)$ & 0.275 \\
\hline Number of male sexual partners in the past 6 months ${ }^{b}$ & & & & 0.001 \\
\hline 0 & $7(2.8)$ & 1.00 & 1.00 & \\
\hline 1 & $76(6.7)$ & $2.35(1.08-5.09)$ & $1.61(0.73-3.55)$ & 0.239 \\
\hline $2-5$ & $169(8.9)$ & $3.11(1.46-6.62)$ & $2.18(1.01-4.72)$ & 0.047 \\
\hline$>5$ & $36(12.6)$ & $4.89(2.18-10.99)$ & $3.19(1.40-7.26)$ & 0.006 \\
\hline Primary venue to find sexual partners ${ }^{b}$ & & & N.S. & \\
\hline No male sexual partners & $14(6.3)$ & 1.00 & & \\
\hline Offline & 79 (10.6) & $1.75(0.99-3.09)$ & & \\
\hline Online & $109(7.5)$ & $1.59(0.91-2.78)$ & & \\
\hline Money boys from clubs & $84(7.8)$ & $1.53(0.87-2.69)$ & & \\
\hline Other venues & $2(2.2)$ & $0.59(0.13-2.61)$ & & \\
\hline Condom use during anal intercourse in the past 6 months ${ }^{b}$ & & & & $<0.001$ \\
\hline Inconsistent & $174(11.0)$ & $2.04(1.61-2.59)$ & $1.87(1.46-2.38)$ & $<0.001$ \\
\hline Consistent & $114(5.7)$ & 1.00 & 1.00 & \\
\hline
\end{tabular}

${ }^{\mathrm{a}} H R$ Hazard Risk

b These characteristics data were collected since $2014(N=3579)$

analysis to explore the changes in HIV-related behaviors in this sample of the MSM population. The results showed significant changes in sexual behaviors over time among this open cohort of MSM in Chengdu from 2014 to 2018. The rate of condom use increased from $42.4 \%$ in 2014 to $55.8 \%$ in 2018 (trend test $p<0.001$ ). In addition, the lifetime HIV testing rate also increased from $51.2 \%$ in 2014 to $75.2 \%$ in 2018 (trend test $p<$ 0.001). This is consistent with the trend in HIV incidence density among MSM in Chengdu. Therefore, we conclude that improved sexual behaviors and HIV testing may have partially contributed to the reduction of HIV incidence density in Chengdu. Furthermore, our study found about 30\% of MSM in Chengdu obtained their primary sex from money boys in clubs, who offer commercial sex services to men. In the twentieth century, there was a large migration from rural areas to urban areas in southwest China. Many young men in their twenties have increasingly entered the sex trade, and are known as money boys [33]. This subgroup is six times more likely to be infected with HIV than other MSM in Chengdu [34]. In line with another studies, we considered that money boys and their clients may act as bridging populations for HIV transmission from highrisk MSM to low-risk MSM [35]. These susceptible subpopulations among MSM require more efforts in implementing both behavioral and biomedical interventions. Consistent with previous studies in China, we founded that inconsistent condom use remained the most easily identifiable risk factor for HIV incidence in 
this study [12, 36, 37]. One study conducted in Beijing revealed that increased risk of HIV infection was strongly associated with lower level of perceived social norms about condom use [38]. It shows the continuing importance of behavioral interventions for HIV prevention among Chinese MSM, even in an era of high rates of testing and treatment. Unprotected anal intercourse (UAI) is considered the most prominent risk factor for HIV infection not only in China but worldwide $[39,40]$. Some researchers suggested that feelings of trust, desired intimacy and pleasure could lead MSM to not use condoms during anal sex [37]. Therefore, the guidelines on HIV prevention for key populations published by WHO in 2014 have highlighted that increasing the availability, accessibility, affordability and use of condoms among MSM is an essential component of the HIV response [41].

Effective prevention strategies are always the key to decrease new HIV infections among MSM. In addition to advancing promotion of behavioral change interventions such as condom use among MSM in response to the WHO recommendations, other biomedical interventions such as HIV testing and ART have also been promoted in China during the past 10 years [42]. Several modeling studies using the Asian Epidemic Model and compartmental models indicated that condom use in combination with ART could substantially reduce HIV incidence among MSM in China [43-45]. In China, ART coverage also benefits from increased VCT services [43]. Another modeling study conducted in Guangzhou, China concluded that the increase of HIV incidence had been curbed since the AIDS comprehensive Prevention project which was launched in 2010 to improve condom use, HIV testing and ART coverage [46].

This study is subject to several limitations. First, the result may be biased due to the convenience-sampling method. Participants included in our study were active service users of a gay-friendly NGO, and they tend to be younger and highly educated. Findings of this study might not be generalizable to other MSM populations, such as non-VCT users and MSM in other cities. Despite the relatively large sample size, we included only those with two or more HIV testing records at the NGO during the study period. Second, reporting bias may exist due to the nature of self-reported data and the sensitive questions about sexual behaviors. Third, except for sexual behaviors, other factors (e.g. drug use) associated with HIV incidence among MSM were underinvestigated in the present study.

\section{Conclusions}

The incidence density of HIV among MSM decreased gradually from 2012 to 2018, which was potentially related to the successful comprehensive HIV prevention strategies in Chengdu. Multiple male sexual partnerships and inconsistent condom use continue to be risk factors associated with HIV occurrence, which highlights the need for promoting HIV/AIDS-related knowledge, enhanced behavioral interventions, and strengthening related services for vulnerable populations.

\begin{abstract}
Abbreviations
MSM: Men who have sex with men; NGO: Non-governmental organization; VCT: Voluntary counseling and testing services; PYs: Person-years; AHR: Adjusted Hazard Ratio; PLWH: People living with HIV/AIDS; CDC: Center for disease control and prevention; ART: Antiretroviral treatment; PrEP: Preexposure prophylaxis
\end{abstract}

\section{Acknowledgements}

We would like to thank all the participants. We especially thank the assistance of Chengdu Tongle Health Consulting Service Center for collaborating in the data collection.

\section{Authors' contributions}

Conceptualization, $\mathrm{SG}, J \mathrm{HL}, \mathrm{XY}, \mathrm{CH}$; Data curation, $\mathrm{LP}, \mathrm{XY}$; Formal analysis, JHL, XY, $\mathrm{SG}, \mathrm{LP}$, JBL; Investigation, JHL, XY, SG, JG, CH, WC, LP, DW, YD, XW; Resources, XW; Writing - original draft, XY; Writing - review and editing, XY, SG, JHL, WC, PML, JTL; YH, HZ; Contributed to the work of quality control, XY, SG, JHL; Revised the manuscript and provided scientific comments, JBL, YH, HZ. All authors assisted in data interpretation and gave comments to intellectual content of the manuscript. The author(s) read and approved the final manuscript.

\section{Funding}

This research was supported by the National Natural Science Foundation of China (81803334, 71774178, 71974212), a Major Infectious Disease Prevention and Control of the National Science and Technology Major Project of China (2018ZX10715004), Science and Technology Planning Project of Guangdong Province (2017A020212006), and Science and Technology Research Project of Guangzhou (201607010332, 201607010368). The funder had no role in the design of study and collection, analysis, and interpretation of data and in writing the manuscript.

\section{Availability of data and materials}

The data used in the study was not publicly available. The datasets used and analyzed during the current study are available from the corresponding author on reasonable request.

\section{Declarations}

\section{Ethics approval and consent to participate}

This study was reviewed by the ethics committee of School of Public Health, Sun Yat-sen university and considered exempt from full ethics review because it used an anonymized secondary routine dataset. The approval number is [2020] 065.

\section{Consent for publication}

Not applicable.

\section{Competing interests}

The authors declare that they have no competing interest.

\section{Author details}

'School of Public Health, Sun Yat-sen University (North Campus), No.74, Zhongshan second road, Guangzhou, China. ${ }^{2}$ Graduate School of Public Health, St. Luke's International University, Tokyo, Japan. ${ }^{3}$ Center for Evidence Synthesis in Health, School of Public Health, Brown University, Providence, Rl, USA. ${ }^{4}$ Centre for Health Behaviours Research, JC School of Public Health and Primary Care, The Chinese University of Hong Kong, Hong Kong, China. ${ }^{5}$ Sun Yat-sen Global Health Institute, Sun Yat-sen University, Guangzhou, China.

${ }^{6}$ Chengdu Tongle Health Consulting Service Center, Chengdu, China. ${ }^{7}$ School of Public Health (Shenzhen), Sun Yat-sen University, Shenzhen, China.

${ }^{8}$ Department of Clinical Research, Sun Yat-sen University Cancer Center; State Key Laboratory of Oncology in South China; Collaborative Innovation Center for Cancer Medicine, Guangzhou, China. 


\section{Received: 12 June 2020 Accepted: 13 April 2021}

\section{Published online: 26 April 2021}

\section{References}

1. Yang X, Wang Z, Wang X, Ma T, Xue H, He Y, et al. Behavioral intention to initiate antiretroviral therapy (ART) among Chinese HIV-infected men who have sex with men having high CD4 count in the era of "treatment for all". Am J Mens Health. 2019;13(1):1557988319828615. https://doi.org/10.1177/1 557988319828615

2. Alfvén T, Erkkola T, Ghys PD, Padayachy J, Warner-Smith M, Rugg D, et al. Global AIDS Reporting-2001 to 2015: lessons for monitoring the sustainable development goals. AIDS Behav. 2017;21(Suppl 1):5-14. https://doi.org/10.1 007/s10461-016-1662-9.

3. Liu Z, Shi O, Yan Q, Fang Q, Zuo J, Chen Y, et al. Changing epidemiological patterns of HIV and AIDS in China in the post-SARS era identified by the nationwide surveillance system. BMC Infect Dis. 2018;18(1):700. https://doi. org/10.1186/s12879-018-3551-5.

4. Zheng S. The growing threat of China's HIV epidemic. Lancet Public Health. 2018;3(7):e311. https://doi.org/10.1016/\$2468-2667(18)30098-7.

5. China Health and Family Planning Commission: 2015 China AIDS Response Progress Report In Edited by Commission CHaFP: Center for Disease Control; 2015. Available from: http://www.commuhealtibet.org/wp-content/ uploads/2016/11/CHN_narrative_report_2015.pdf

6. State Council AIDS Working Committee Office (SCAWCO). China 2010 UNGASS Country Progress Report (2008-2009). In: Ministry of Health of the People's Republic of China, Beijing, China; 2010. Available from: https://data. unaids.org/pub/report/2010/china_2010_country_progress_report_en.pdf.

7. National Center for AIDS/STD Control and Prevention CC: Progress of AIDS prevention and treatment in China. 2012.

8. Chu Z-X, Xu J-J, Zhang Y-H, Zhang J, Hu Q-H, Yun K, et al. Poppers use and sexual partner concurrency increase the HIV incidence of MSM: a 24-month prospective cohort survey in Shenyang, China. Sci Rep. 2018;8(1):24. https:// doi.org/10.1038/s41598-017-18127-x.

9. Beyrer C, Baral SD, van Griensven F, Goodreau SM, Chariyalertsak S, Wirtz AL, et al. Global epidemiology of HIV infection in men who have sex with men. Lancet. 2012;380(9839):367-77. https://doi.org/10.1016/S0140-6736(12)60821-6.

10. Busch MP, Pilcher CD, Mastro TD, Kaldor J, Vercauteren G, Rodriguez W, et al. Beyond detuning: 10 years of progress and new challenges in the development and application of assays for HIV incidence estimation. AIDS. 2010;24(18):2763-71. https://doi.org/10.1097/QAD.0b013e32833f1142.

11. Sun X, Lu F, Wu Z, Poundstone K, Zeng G, Xu P, et al. Evolution of information-driven HIV/AIDS policies in China. Int J Epidemiol. 2010;39 Suppl 2(Suppl 2):ii4-ii13.

12. Chen Q, Sun Y, Sun W, Hao M, Li G, Su X, et al. Trends of HIV incidence and prevalence among men who have sex with men in Beijing, China: nine consecutive cross-sectional surveys, 2008-2016. PLoS One. 2018;13(8): e0201953. https://doi.org/10.1371/journal.pone.0201953.

13. Wang Q-Q, Chen X-S, Yin Y-P, Liang G-J, Zhang R-L, Jiang N, et al. HIV prevalence, incidence and risk behaviours among men who have sex with men in Yangzhou and Guangzhou, China: a cohort study. J Int AIDS Soc. 2014;17(1):18849. https://doi.org/10.7448/IAS.17.1.18849.

14. UNAIDS/WHO Working Group on Global HIV/AIDS/STI Surveillance, World Health Organization, UNAIDS. When and how to use assays for recent infection to estimate HIV incidence at a population level. Geneva: World Health Organization; 2011. p. 48. Available from: https://www.who.int/hiv/ pub/surveillance/sti_surveillance/en/

15. Cui Y, Guo W, Li D, Wang L, Shi CX, Brookmeyer R, et al. Estimating HIV incidence among key affected populations in China from serial crosssectional surveys in 2010-2014. J Int AIDS Soc. 2016;19(1):20609. https://doi. org/10.7448/IAS.19.1.20609.

16. Li Q, Li X, Luo Y, Fang D, Chen J, Zhang X, et al. HIV incidence and cohort retention among men who have sex with men in Hangzhou, China: a prospective cohort study. Medicine (Baltimore). 2019;98(40):e17419. https:// doi.org/10.1097/MD.0000000000017419.

17. Zhang W, Xu J-J, Zou H, Zhang J, Wang N, Shang H. HIV incidence and associated risk factors in men who have sex with men in Mainland China: an updated systematic review and meta-analysis. Sex Health. 2016. https:// doi.org/10.1071/SH16001.

18. Wu Z. Progress and challenge of HIV prevention in China. Zhonghua Yu Fang Yi Xue Za Zhi. 2018;52(12):1204-9. https://doi.org/10.3760/cma.j.jssn.02 53-9624.2018.12.002.
19. Feng Y, Bu K, Li M, Zhang X, Jin S, Wang L. Meta-analysis of HIV infection incidence and risk factors among men who have sex with men in China. Zhonghua Liu Xing Bing Xue Za Zhi. 2015;36(7):752-8.

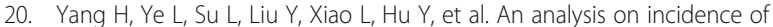
HIV-1 epidemics among men who have sex with men in Sichuan Province during 2011-2015. Zhonghua Yu Fang Yi Xue Za Zhi. 2019:53(3):327-9. https://doi.org/10.3760/cma.j.issn.0253-9624.2019.03.018.

21. Duan Y, Zhang H, Wang J, Wei S, Yu F, She M. Community-based peer intervention to reduce HIV risk among men who have sex with men in Sichuan province, China. AIDS Educ Prev. 2013;25(1):38-48. https://doi.org/1 0.1521/aeap.2013.25.1.38.

22. Xu JL, Jike KCN, Ma Y, Yu G, Wang J, Wang K, et al. Effects and associated factors of HIV/AIDS anti-retroviral therapy in Liangshan Yi autonomous prefecture, Sichuan Province. Zhonghua Yu Fang Yi Xue Za Zhi. 2018;52(6): 668-72. https://doi.org/10.3760/cma.j.issn.0253-9624.2018.06.018.

23. Chow EPF, Lau JTF, Zhuang X, Zhang X, Wang Y, Zhang L. HIV prevalence trends, risky behaviours, and governmental and community responses to the epidemic among men who have sex with men in China. Biomed Res Int. 2014;2014:607261.

24. Liang L, Zhang J, Liu L, Luo Y, Pei X, Hu Y. Infection status of HIV and its influence factors among men who have sex with men in Sichuan province. Zhonghua Yu Fang Yi Xue Za Zhi. 2014;48(11):980-4.

25. Sewell J, Cambiano V, Miltz A, Speakman A, Lampe FC, Phillips A, et al. Changes in recreational drug use, drug use associated with chemsex, and HIV-related behaviours, among HIV-negative men who have sex with men in London and Brighton, 2013-2016. Sex Transm Infect. 2018;94(7):494-501. https://doi.org/10.1136/sextrans-2017-053439.

26. Peng Z, Yang H, Norris J, Chen X, Huan X, Yu R, et al. HIV incidence and predictors associated with retention in a cohort of men who have sex with men in Yangzhou, Jiangsu Province, China. PLoS One. 2012;7(12):e52731. https://doi.org/10.1371/journal.pone.0052731.

27. Garofalo R, Hotton AL, Kuhns LM, Gratzer B, Mustanski B. Incidence of HIV infection and sexually transmitted infections and related risk factors among very Young men who have sex with men. J Acquir Immune Defic Syndr. 2016;72(1):79-86. https://doi.org/10.1097/QAl.0000000000000933.

28. Han M, Pan PL, Wu GH, Zhou C, Yao Y, Luo J, et al. Estimating HIV incidence rates among MSM in an urban area of Chongqing using three approaches. Biomed Environ Sci. 2017;30(12):913-6. https://doi.org/10.3967/bes2017.122.

29. Liu G, Lu H, Wang J, Xia D, Sun Y, Mi G, et al. Incidence of HIV and syphilis among men who have sex with men (MSM) in Beijing: an open cohort study. PLoS One. 2015;10(10):e0138232. https://doi.org/10.1371/journal.pone.0138232.

30. Grulich AE, Guy R, Amin J, Jin F, Selvey C, Holden J, et al. Population-level effectiveness of rapid, targeted, high-coverage roll-out of HIV pre-exposure prophylaxis in men who have sex with men: the EPIC-NSW prospective cohort study. Lancet HIV. 2018;5(11):e629-37. https://doi.org/10.1016/S23 52-3018(18)30215-7.

31. Heuker J, Sonder GJB, Stolte I, Geskus R, van den Hoek A. High HIV incidence among MSM prescribed postexposure prophylaxis, 2000-2009: indications for ongoing sexual risk behaviour. AIDS. 2012;26(4):505-12 https://doi.org/10.1097/QAD.0b013e32834f32d8.

32. Meng X, Zou H, Fan S, Zheng B, Zhang L, Dai X, et al. Relative risk for HIV infection among men who have sex with men engaging in different roles in anal sex: a systematic review and meta-analysis on global data. AIDS Behav. 2015;19(5):882-9. https://doi.org/10.1007/s10461-014-0921-X.

33. Huynh A, Yu N, Zhang J, Chevrier C, Lazarus L, Blanchard J, et al. Money boys in Chengdu, China: migration, entrepreneurial precarity and health service access. Cult Health Sex. 2020;22(12):1333-48. https://doi.org/10.1 080/13691058.2019.1679393.

34. Feng $Y$, Wu Z, Detels R, Qin G, Liu L, Wang X, et al. HIV/STD prevalence among men who have sex with men in Chengdu, China and associated risk factors for HIV infection. J Acquir Immune Defic Syndr. 2010;Suppl 1(Suppl 1):S74-80.

35. Wong FY, Huang ZJ, He N, Smith BD, Ding Y, Fu C, et al. HIV risks among gay- and non-gay-identified migrant money boys in Shanghai, China. AIDS Care. 2008;20(2):170-80. https://doi.org/10.1080/09540120701534707.

36. Li R, Wang H, Pan X, Ma Q, Chen L, Zhou X, et al. Prevalence of condomless anal intercourse and recent HIV testing and their associated factors among men who have sex with men in Hangzhou, China: a respondent-driven sampling survey. PLoS One. 2017;12(3):e0167730. https://doi.org/10.1371/ journal.pone.0167730.

37. Sun X, Wang C, Zhao K, Zhang L, Li M, Sun D, et al. HIV Seroconversion and types of relationships among men who have sex with men: a cohort study 
in China. J Acquir Immune Defic Syndr. 2020;83(4):365-72. https://doi.org/1 0.1097/QAl.0000000000002264

38. Fan S, Lu H, Ma X, Sun Y, He X, Li C, et al. Behavioral and serologic survey of men who have sex with men in Beijing, China: implication for HIV intervention. AIDS Patient Care STDs. 2012;26(3):148-55. https://doi.org/10.1 089/apc.2011.0277.

39. Hessou SPH, Glele-Ahanhanzo Y, Adekpedjou R, Ahoussinou C, Djade CD, Biaou $A$, et al. HIV incidence and risk contributing factors among men who have sex with men in Benin: a prospective cohort study. PLoS One. 2020; 15(6):e0233624. https://doi.org/10.1371/journal.pone.0233624.

40. Schilder AJ, Anema A, Pai J, Rich A, Miller CL, Chan K, et al. Association between childhood physical abuse, unprotected receptive anal intercourse and HIV infection among young men who have sex with men in Vancouver, Canada. PLoS One. 2014;9(6):e100501. https://doi.org/10.1371/ journal.pone.0100501.

41. World Health Organization. WHO Guidelines Approved by the Guidelines Review Committee. In: Consolidated Guidelines on HIV Prevcention, Diagnosis, Treatment and Care for Key Populations. Geneva: World Health Organization; 2014.

42. Tao J, Vermund SH, Lu H, Ruan Y, Shepherd BE, Kipp AM, et al. Impact of depression and anxiety on initiation of antiretroviral therapy among men who have sex with men with newly diagnosed HIV infections in China. AIDS Patient Care STDs. 2017;31(2):96-104. https://doi.org/10.1 089/apc.2016.0214.

43. Tao L, Liu M, Li S, Liu J, Wang N. Condom use in combination with ART can reduce HIV incidence and mortality of PLWHA among MSM: a study from Beijing, China. BMC Infect Dis. 2018;18(1):124. https://doi.org/10.1186/s12 879-018-3026-8

44. Li J, Gilmour S, Zhang H, Koyanagi A, Shibuya K. The epidemiological impact and cost-effectiveness of HIV testing, antiretroviral treatment and harm reduction programs. AIDS. 2012;26(16):2069-78. https://doi.org/10. 097/QAD.0b013e3283574e54.

45. Li J, Peng L, Gilmour S, Gu J, Ruan Y, Zou H, et al. A mathematical model of biomedical interventions for HIV prevention among men who have sex with men in China. BMC Infect Dis. 2018;18(1):600. https://doi.org/10.1186/ s12879-018-3516-8.

46. Liu JH, Cheng WB, Xu HF, Gu J, Hao C, He WY, et al. Prevention effectiveness of the "internet plus-based AIDS comprehensive prevention service system" among MSM in Guangzhou: a dynamic model of infectious disease. Zhonghua Liu Xing Bing Xue Za Zhi. 2019;40(10):1227-33. https:// doi.org/10.3760/cma.jissn.0254-6450.2019.10.011.

\section{Publisher's Note}

Springer Nature remains neutral with regard to jurisdictional claims in published maps and institutional affiliations.

Ready to submit your research? Choose BMC and benefit from:

- fast, convenient online submission

- thorough peer review by experienced researchers in your field

- rapid publication on acceptance

- support for research data, including large and complex data types

- gold Open Access which fosters wider collaboration and increased citations

- maximum visibility for your research: over $100 \mathrm{M}$ website views per year

At $\mathrm{BMC}$, research is always in progress.

Learn more biomedcentral.com/submissions 